\title{
DUAS LEITURAS DE UM MOVIMENTO: NORBERT ELIAS E THEODOR W. ADORNO, SOBRE O PROCESSO CIVILIZADOR ${ }^{1}$
}

\author{
READING MOVEMENT, TWO TIMES: NORBERT ELIAS AND \\ THEODOR W. ADORNO, ON THE CIVILIZATION PROCESS
}

\section{DOS LECTURAS DE UN MOVIMIENTO: LEITURAS DE UM MO- VIMENTO: NORBERT ELIAS Y THEODOR W. ADORNO, SOBRE EL PROCESO CIVILIZADOR}

Alexandre Fernandez Vaz ${ }^{2}$

Resumo O presente trabalho propõe uma análise do texto de Norbert Elias que corresponde ao discurso por ele proferido por ocasião do recebimento do prêmio Theodor W. Adorno, em Frankfurt, 1977. No texto de Elias, intitulado Discurso sobre Adorno: Respeito e Criti$c a$, confluem comentários pessoais e teóricos acercaa respeito de Theodor W. Adorno, seu contemporâneo, mas com o qual teve relação muito superficial. Os comentários de Elias estão centrados, em grande parte, nas dificuldades e apuros do humanismo marxista de Adorno. Suas críticas se referem, principalmente, aos supostos limites impostos pelo pensamento de Marx às reflexões de Adorno. É esse o ponto principal da análise aqui exibida,

\footnotetext{
O trabalho é o resultado parcial do programa de pesquisas Teoria Crítica, Racionalidades e Educação (IV), financiado pelo CNPq e realizado no Núcleo de Estudos e Pesquisas Educação e Sociedade Contemporânea. Uma versão dele foi apresentada no Colóquio Internacional Norbert Elias, na UFPR, em Curitiba, 2000, com o título "O octogenário volta para casa e é bem-vindo": Norbert Elias escreve sobre Theodor W. Adorno. Dela foi publicado apenas um resumo. Outra foi publicada nos anais do VII Seminário de Pesquisa em Educação da Região Sul (ANPED-SUL), 2008, sob o título Cultura, esclarecimento e civilização em duas leituras: Norbert Elias e Theodor W. Adorno. Ele foi, no ano seguinte, discutido em atividade no PPGE/UDESC. Ele pode ser ainda encontrado, em versão outra, ainda em Alexandre Fernandez Vaz. Adorno por Elias, para além de Elias: questões para uma Teoria Crítica do Presente. X Jornadas de Sociología. Facultad de Ciencias Sociales, Universidad de Buenos Aires, Buenos Aires, 2013. Muitas partes dele encontram-se em meu livro Sport und Sportkritik in Kultur- und Zivilisationsprozess: Analysen nach Adorno und Horkheimer, Elias und DaMatta, publicado pela Afra Verlag, em Frankfurt, 2004. Nesse texto, corrijo e amplio vários dos aspectos não presentes antes.

2 Universidade Federal de Santa Catarina. Florianópolis-SC / Brasil.
} 
que ao centrar-se na problematização da crítica de Elias, aponta argumentos que procuram adversar as observações a respeito da Obra de Adorno, sobretudo no que diz respeito à sua relação com o marxismo.

Palavras-chave: Elias, Norbert; Adorno, Theodor W.; Sociologia; Processo civilizador.

Abstract The aim in this paper is to present some analysis of a Norbert Elias' Speech, when he got the Theodor W. Adorno-Pries, in Frankfurt, 1977. The text is called Speech on Adorno: Respect and Critic, and has personal and theoretical commentaries on Adorno, whose relation with Elias was no more than superficial. Elias's commentaries are on a kind of Marxist Humanism of Adorno. The critical observations are especially on the limits of Marx's Theory absorbed by Adorno. In this point, I make my critical approach to Elias' observations, getting into arguments against his Interpretation of Adorno's Work, especially concerning its relation with Marxism.

Keywords: Elias, Norbert; Adorno, Theodor W.; Sociology; Civilization Process.

Resumen En este trabajo analizo el texto de Norbert Elias que corresponde al discurso por el que se profirió cuando le fue otorgado el premio Theodor W. Adorno, en Frankfurt, 1977. El en texto de Elias, que se llama Discurso sobre Adorno: Respeto y Crítica, confluyen análisis teóricos y personales sobre Theodor W. Adorno, su contemporáneo, con lo cual tuvo contacto no más que superficial. Los comentarios de Elias están centrados, en gran parte, en las dificultades y los apuros del humanismo marxista de Adorno. Sus críticas se refieren a los supuestos límites por el pensamiento de Marx a las reflexiones de Adorno. Éste es el punto principal de mi análisis, cuando problematizo la crítica de Elias, contraponiendo argumentos a las observaciones sobre la Obra de Adorno, en especial su relación con el marxismo.

Palabras clave: Elias, Norbert; Adorno, Theodor W.; Sociología; Proceso civilizador.

\section{“O OCTOGENÁRIO VOLTA PARA CASA, E É BEM-VINDO"}

Em 1977, Norbert Elias foi agraciado com o prêmio Theodor W. Adorno, concedido pela municipalidade de Frankfurt, Alemanha, e pela Editora Suhrkamp, casa editorial responsável pela publicação de $O$ processo civilizador, do próprio Elias, assim como da obra de Adorno. s.A concessão do prêmio - também outorgado posteriormente a figuras como Jürgen Habermas, Jean-Luc Godard, Zygmunt Bauman, Jaques Derrida e Judith Butler - reveste-se de importância ainda maior ao se observar que Elias foi escolhido para sua primeira edição. Certamente um reconhecimento, ainda que tardio, de um dos grandes intelectuais do século XX, judeu e alemão, europeu, como fez questão de destacar na famosa entrevista que antecede seu texto autobiográfico em Norbert Elias über sich Selbst (ELIAS, 1996). A carreira de Elias se desenvolvera, até perto do fim da vida, longe do país natal. Nos últimos anos, dividia-se em sua casa de Amsterdã e um pequeno apartamento em Bielefeld, 
em cuja universidade lecionava.

Os comentários do presente texto referem-se às diferenças e às proximidades entre Elias e Adorno, tendo como horizonte o que ambos concebem como cultura e civilização. Eles tomam como documento central nessa aproximação ao tema a conferência proferida por Elias quando do recebimento do prêmio citado, em 2 de outubro de 1977, e publicado em um pequeno livro, com o discurso laudatório do sociólogo e Wolf Lepenies, pronunciado no mesmo dia. A intervenção de Elias, intitulada Discurso sobre Adorno: Respeito e Crítica (ELIAS; LEPENIES, 1977), diz respeito, em grande parte, àquele que empresta seu nome ao prêmio, como costuma acontecer nessas ocasiões. Ela combina comentários pessoais, reconstrução historiográfica e reflexões teóricas.

Em vários momentos, Elias contrapõe-se a Adorno arguindo sua própria arquitetura teórica, desenvolvida, sobretudo, a partir da elaboração do livro sobre o processo civilizador (ELIAS, 1988). Elias não foge ao seu estilo: por um lado procura garantir a indissociabilidade entre as experiências pessoais históricas e teóricas, por outro recolocar e legitimar aspectos epistemológicos da Figurationssoziologie, a Sociologia das Configurações. Ao fazer isso, o grande sociólogo coloca a si mesmo como objeto da metodologia que desenvolveu.

Norbert Elias conhecera Theodor W. Adorno no início dos anos de 1930, quando eram jovens professores-assistentes na Universidade Johann Wolfgang Goethe, em Frankfurt. Ambos tinham ascendência judaica e igualmente viveriam a perseguição e o exílio, parcialmente no mesmo país, a Inglaterra, onde Elias desenvolveu, não sem dificuldades e desvios, a maior parte de sua carreira, e Adorno apenas permaneceu durante três anos, em condição acadêmica precária, antes de encontrar o abrigo nos Estados Unidos, primeiro em New York, depois em Los Angeles. Embora tenham trabalhado no mesmo edifício em Frankfurt e, segundo Elias, frequentado círculos sociais muito próximos, não tiveram por essa época - como tampouco posteriormente - contato mais que superficial.

Norbert Elias trabalhou em Frankfurt como assistente de Karl Mannheim - apenas quatro anos mais velho e com quem, como relata Lepenies (1977) não manteve relação assimétrica -, teve à sua disposição uma sala no segundo andar do Instituto de Pesquisa Social, posteriormente tornado mundialmente famoso como embrião da chamada Escola de Frankfurt. A Universidade alugava sala do Instituto, órgão com autonomia financeira e intelectual em relação aos programas acadêmicos, ainda que ligado a ela institucionalmente. O Instituto tinha como diretor desde 1929 Max Horkheimer, cujas relações com Mannheim não eram das melhores. Adorno (1997), na condição de assistente de Horkheimer, escreveria em 1937 um ensaio muito crítico à Sociologia do Conhecimento de Mannheim. Ele viria a público apenas em 1953, em Prismas (ADORNO, 1997h) um de seus livros-chave, o que mostra o espírito de disputa daquela década, mas também a permanência dele muitos anos depois. As escaramuças intelectuais encontraram eco na não aproximação dos jovens assistentes, que viriam a desenvolver, ironicamente, caminhos teóricos que os levaram a debater temas de comum interesse, eventualmente com abordagens semelhantes, mas sempre independentes um do outro.

É profícua a leitura de aspectos das obras de dois grandes teóricos como Elias e Ador- 
no, colocadas frente a frente, para que se possa, como num jogo de espelhos, observar as diferenças e encontros, mesmo que eletivos. O debate torna-se importante também porque ambos, para além das semelhanças pontuais, dedicaram-se a empreendimentos teóricos de vulto, procurando entender o processo de constituição da cultura e da civilização. De alguma forma, respondiam ao espírito do tempo, que viu emergir obras, como as deles, fundadoras, com amplas pretensões, impactadas pela história e pela política e amparadas em perspectivas fortemente universalistas, algo hoje muito menos em voga. Outro exemplo certamente é $A$ condição humana, de Hannah Arendt, publicado em 1958.

Se os empreendimentos de cada um tiveram temáticas mais ou menos comuns, foram, no entanto, diversos no estilo e no ponto de vista. Elias (1988) procura traçar, a partir de fontes documentais, principalmente da sociedade de corte francesa, o curso sócio-histórico que se estrutura em um processo contínuo, cuja direção pode ser identificada por um lado na constituição dos Estados, na centralização da cobrança de impostos e no monopólio da violência, e por outro na internalização de normas e coações antes externas, no controle das pulsões, sentimentos e emoções. Tudo isso ganha sentido por configurações que resultam da instituição de redes cada vez mais complexas de interdependência. Uma sociedade mais civilizada teria redes mais extensas e entrelaçadas, com os correspondentes mecanismos de controle e autocontrole progressivamente mais estruturados. Sociedades mais civilizadas seriam, portanto, menos sujeitas a transformações bruscas ou à violência continuada. Haveria nesse processo um movimento racional, ascendente, mas não planejado. $\mathrm{O}$ processo civilizador, em movimento que no Ocidente seria universal, pode ser entendido, portanto, apenas na medida em que se realiza.

Por sua vez, Theodor W. Adorno elabora sua crítica à cultura (como civilização, ecoando o Freud de O mal-estar na cultura), com Max Horkheimer (1997), por meio de um discurso crítico e filosófico que se configura, em momento decisivo de suas obras, como um projeto. De fato, em Dialética do esclarecimento muitos temas que foram investigados pelos autores, como também por seus colaboradores, aparecem em formato de teses bem argumentadas, mas não propriamente comprovadas. Pesquisas empíricas, como a sobre a personalidade autoritária e vários dos artefatos da indústria do entretenimento, a exemplo da música no rádio e o horóscopo, bem como, especulações com material bibliográfico e observações aparentemente prosaicas, oferecem sustentáculo para as hipóteses e argumentos desenvolvidos. Somam-se a isso os exemplos da literatura - expressão, da mesma maneira que outras formas de arte, do inconsciente do tempo, como escreveu Adorno - para afirmarem e criticarem o projeto de constituição da razão, marcado pela passagem do mito ao Iluminismo, pela dominação da natureza, seja de forma mágica ou científica, uma, na verdade, antecipando e se combinando com a outra. Compõem esse mesmo quadro os esquemas da indústria cultural e os mecanismos de dominação política. Promove-se aí um tipo de sujeito - ou de des-subjetivação - que encontraria seus destinos no caráter irracional da razão. Esse work-in-progress teria boas respostas nas décadas seguintes, quando Horkheimer e, principalmente, Adorno, desenvolveram uma obra muito extensa, complexa e inovadora.

Lepenies (1977), no discurso que faz em homenagem a Elias, por ocasião do rece- 
bimento deste do Prêmio Adorno, assinala, mesmo que de maneira breve, algumas das aproximações entre os dois autores que, entre diferenças, se aproximariam no que se refere à construção teórica, que se dá em movimento com a pesquisa empírica, ao lugar do corpo em cada uma das perspectivas, assim como, ao movimento de coerção - de externa para interna no curso da civilização e da cultura.

A conferência de Elias é o único escrito em que ele se refere de forma enfática a Adorno. Na ausência de um que o frankfurtiano houvesse escrito sobre o sociólogo das configurações, ganha o texto de 1977 uma insuspeitada importância. Outra menção feita por Elias a Adorno, muito ligeira, encontra-se no prólogo de Os alemães (ELIAS, 1989), ocasião que não chega a constituir uma peça de debate - o que, aliás, é uma pena, uma vez que haveria o que contrastar entre as interpretações de ambos acerca da barbárie perpetrada pelos teutônicos, cujo ponto culminante é a Segunda Guerra Mundial.

A exposição a seguir se guia, em linhas gerais, pela dinâmica do próprio texto de Elias. Dessa forma, atém-se, sobretudo, às questões que ele levanta sobre Adorno, tentando discuti-las em seu conteúdo interno e tessitura teórica. Com isso, pretende-se identificar alguns pontos de tensão e/ou aproximação nas obras de ambos, para compor uma reflexão que seja a respeito de Elias, mas também acerca de Adorno.

\section{Norbert Elias escreve sobre Theodor W. Adorno}

Elias inicia seu discurso lembrando o quanto foi longo o caminho para o reconhecimento de sua obra, agora valorizada pelo prêmio Theodor W. Adorno. Há no discurso um misto de ressentimento, alívio e sensação de reconhecimento. Antes de recordar o rico clima cultural que vivera em Frankfurt no início dos anos 1930 - "dos mais ricos e estimulantes de minha vida" (1977, p. 40) -, Elias demarca sua relação pessoal com a Alemanha e seu universo intelectual: "O octogenário volta para casa, e é bem-vindo" (1977, p. 37). Depois de anos vivendo fora, onde seguiria, Elias reencontra o universo no qual se formou intelectualmente, a longa tradição do Idealismo Alemão e da emergente Sociologia dos irmãos Weber, dos salões e cafés.

É esse contexto, o do clima intelectual vivido em Frankfurt, que servirá para Elias como ponto de partida para as referências a Adorno. Certamente que um ouvira falar do outro nos círculos em que se moviam (1977, p. 39). Olhando retrospectivamente, Elias aponta similaridades entre eles, manifestas ao longo da vida de ambos: o interesse pela arte e pela experiência estética - entendidas como esferas fundamentais de conhecimento, inclusive na relação com a investigação acadêmica -, a dificuldade em pensar as grandes questões a partir de apenas uma disciplina, ou ainda o caráter "vivo" dos seminários que cada qual dirigia. Elias destaca a conhecida sensibilidade de Adorno como homme de lettre, destacando suas experimentações linguísticas e o cuidado com a expressão estética da palavra (1977, 40-43). Trata-se de um belo e justo reconhecimento para um autor que ousou dizer que pensava com os ouvidos (ADORNO, 1997g), para o qual expressão estética e comu- 
nicação científica ou filosófica não se excluem, senão que se inserem no mesmo esforço reflexivo e crítico.

Segundo Elias (1977, p. 44), Adorno seria um humanista crítico, condição que mais os deixaria próximos. Um humanista crítico seria reconhecido por duas grandes características, por exercer a solidariedade emocional e intelectual com os oprimidos, outsiders e explorados, e por aproximar conceitos "desumanizados" como política, cultura, economia e sistema, entre outros, às questões mais prementes de homens e mulheres, percebê-los em sua humanidade.

Se Adorno acompanharia Elias na primeira das características, o mesmo não poderia ser dito na segunda. A justificativa de Elias é quase surpreendente: Adorno teria buscado em Marx e Engels a base para o seu humanismo crítico, e com isso teria se deixado levar por um aparato teórico ultrapassado, correspondente ao passado (1977, p. 44-45). Ele seria um marxista humano, ao mesmo tempo ortodoxo e não ortodoxo (1977, p. 47).

Elias argumenta que de fato não se pode negar a importância do marxismo como modelo teórico que coloca em jogo a sociedade e o seu desenvolvimento do ponto de vista dos explorados, sem o qual não se poderia entender as desigualdades de poder características da civilização ocidental. O marxismo, no entanto, seria um bom exemplo de algo que foi planificado para determinado fim, sem que se tenha considerado o imponderável, e que acaba então por tornar-se algo longe da perspectiva inicial (1977, p. 45-47). De um objetivo futuro e utópico, o marxismo tornara-se modelo para Estados poderosos e partidos:

\footnotetext{
A transformação do programa de luta de Marx para os oprimidos e pouco organizados trabalhadores, em programa de governo para o desenvolvimento planificado de poderosos Estados, é um exemplo que mostra as alterações que se apresentam aos resultados antes esperados, no curso de processos imprevistos (1977, p. 47).
}

Elias insiste que o humanismo crítico de Adorno estaria ligado a um modelo teórico ultrapassado, do século anterior, autoritário, dogmático, que se pretende medida de outras teorias e quer convencer que os conflitos de classe da metade do século XIX seriam os mesmos do final do século XX. Para Elias, é fundamental a contemporaneidade de uma teoria. No final de seu discurso, lembrará que a ciência é como que uma corrida de revezamento: "Meu desejo é passar o bastão adiante, e em especial transmitir a coragem de se contrapor tanto às estruturas de autoridade do passado quanto às do presente. [...] ultrapassar as velhas gerações" (1977, p. 65).

É claro que Elias se referia não apenas à obra de Marx e Engels, mas essencialmente à recepção e interpretação que o marxismo experimentou, inclusive como legitimador do terrorismo urbano dos anos de 1970 (1977, p. 62). É certo que Elias não conhecia o marxismo e sua tradição com grande profundidade, uma perspectiva quase sempre ausente em seu trabalho, mesmo em forma de comentário. Na já citada entrevista com a. J. Heerma van Voss e A van Stolk, a Biographical Interview with Norbert Elias, publicada em Reflections on a Life, Elias (1994) afirma que se dedicara a estudar a obra de Marx, que até então desconhecia, no final dos anos 1920, em Heidelberg (p. 34). Ao longo de alguns de seus 
trabalhos, vários de seus comentários a respeito de Marx ou são feitos superficialmente, no marco das generalidades das correntes sociológicas, ou dizem respeito criticamente à experiência do comunismo de caserna (por exemplo, ELIAS, 1991), coincidindo, aliás, com a posição severa que Adorno guardava em relação à União Soviética, sua política bélica e imperialista e sua recusa à autocrítica.

Esse vínculo do marxismo com a violência, destacada também por outros grandes pensadores do século XX, como Hannah Arendt (1993), teve na Alemanha do último terço do século XX um vetor especial. Foi, em alguma medida, a motivação ideológica para um acerto de contas com a história, com o recente passado nazista (ELIAS, 1977, p. 61). É preciso lembrar que a Alemanha foi um dos principais palcos da Guerra Fria, e conservou em diferentes medidas, até 1995, o status de Estado Ocupado. Esses processos, decorrentes do Nacional-Socialismo e da Segunda Guerra, foram muito traumáticos para o país (então dividido em duas partes, situação que durou até 1991), cujo passado permaneceu, como com frequência acontece em situação de trauma, causando mal-estar e ameaçando emergir com violência.

Não é tão simples dizer que o marxismo foi a perspectiva por meio da qual legitimou-se, nesse contexto, a ação do RAF (Rote Armee Faktion - Facção do Exército Vermelho), responsável por uma grande ofensiva terrorista nos anos de 1970 e início dos de 1980 do século passado, na Alemanha. Embora, como já dito, se possa encontrar uma justificativa para a violência, em termos estritamente específicos, no marxismo, não é verdade que ele autorize o terrorismo, como tampouco seria justo dizer que Nietzsche foi a justificação antecipada do nazismo. A RAF protagonizou algumas de suas ações mais marcantes curiosamente no mesmo mês em que Elias recebeu o Prêmio Theodor W. Adorno, nos episódios que constituíram a ofensiva depois chamada de Outubro Sombrio.

Elias localiza nesse quadro as relações algo tensas de Adorno com os estudantes e o movimento estudantil (1977, p. 61) que, de fato, como é amplamente conhecido, não foi isento de dissonâncias. Para Adorno, a violência de setores dos movimentos de contestação reproduziria o espírito totalitário, cuja experiência ele vivera, assim como Elias, como perseguido e exilado. Não foi, no entanto, uma relação apenas de oposição, e certamente não de ruptura com os estudantes. Se, por um lado, Adorno (1997b; 1997e) foi um crítico severo da violência empregada por segmentos do movimento de protesto dos anos de 1960, foi também alguém muito próximo dos estudantes, como se pode observar nos seminários que ministrou ou nos relatos de assistentes e alunos (ADORNO, 1974; BECKER-SCHMIDT, 1991; ). Elias (1977, p. 58-60) evoca uma conferência de Adorno (1997d) sobre as dificuldades de elaboração social e memorialística do passado. Para Elias, o pavor de Adorno frente à possibilidade do renascimento do nazismo, visto que as condições objetivas para isso sobreviviam e sobrevivem, alimentara sua repulsa à violência manifesta por segmentos dos movimentos de protesto dos anos de 1960 do século passado.

Ao retomarmos a interpretação de Elias, segundo a qual a estrutura teórica das análises de Adorno estaria centrada no marxismo, raiz, também, da sua fragilidade; Elias considera que a adesão ao marxismo provocaria uma "paralisia no pensamento": "A coragem 
para seguir pensando está quebrada. Essa fé na autoridade, que se trata de uma doença, condena os seres humanos a uma eterna existência na condição de epígonos" (1977, p. 52).

Embora reconheça em Adorno um pensador autônomo (Selbständiger Denker), Elias afirma que ele não teria tido como escapar das dificuldades em assimilar a contradição expressa pelo marxismo, que como já foi dito, teria sido transformar-se de programa de orientação prática dos oprimidos em ideologia de (Estados e partidos) opressores (1977, p. 53).

Se esse dilema não ficou sem significado para Adorno (53-54), sua resposta seria a resignação, como indicaria a leitura de Minima Moralia: segundo Elias, um lindo texto que zomba do leitor, ao apresentar as questões que, se espera, teriam respostas logo a seguir, mas que não surgem no curso da leitura:

\footnotetext{
Não teria sido esse, talvez, o preço pago pelo seu marxismo humano, uma irresolução em última instância, uma paralisia da capacidade para uma síntese teórica que foi para além de Marx e, por conseguinte a correspondente resignação, o sentimento da precária autorrealização? (1977, p. 54).
}

Esse aprisionamento de Adorno a uma tradição autoritária teria lhe colocado limites intransponíveis. Seria exemplo disso a forma como tratou da relação entre cultura e civilização que, como se sabe, está presente logo no início do livro sobre o Processo Civilizador. Elias comenta o fato de Adorno e Horkheimer terem coordenado um manual acerca de temas da Sociologia, no qual justamente um dos capítulos é denominado Kultur und Zivilisation. Nada demais não fosse o fato de não terem desejado (ou podido) referir-se ao seu trabalho, o que teria sido motivado justamente pelos limites impostos pela adesão ao marxismo.

Não é por má vontade que nessa como em outras ocasiões, com prejuízo para o esforço do conhecimento, minha investigação é ignorada. Ao que me parece, ela não estava compatível com a estrutura de pensamento e o esquema de valores presentes. [...] Os diretores do Instituto não foram tão firmes quanto eu no esforço de avançar no pensamento e na observação.

De fato, nos Soziologische Exkurse, publicados em 1956 pelo Instituto de Pesquisa Social novamente sediado em Frankfurt depois do exílio, o capítulo sobre o tema da relação entre cultura e civilização não se refere, em momento algum à obra de Elias.

Como publicação institucional, os Soziologische Exkurse tinham como objetivo ser um manual que recolocasse em pauta o debate crítico em Sociologia, a qual como de resto também as outras áreas das Humanidades, estava fortemente impregnada pelo nazismo. Mesmo considerando as pretensões do livro, é de se destacar que não haja qualquer referência a Elias, sobretudo em um pequeno artigo que, ao contrário do que é costumeiro com Horkheimer e Adorno, está repleto de notas que indicam outras leituras. Considere-se, no entanto, que o livro mais importante de Elias ainda não havia se tornado um clássico, tendo sua segunda edição aparecido apenas em 1969. Destino, aliás, semelhante ao de outro clássico de nosso tempo, obra chave de Horkheimer e Adorno, a já citada Dialektik der Aufklärung. Lembre-se que ainda no final dos anos 1960 era possível encontrar à venda 
exemplares da primeira edição desse livro, publicada em 1947.

A única referência de Adorno a Elias é acidental, quando cita, em um curso de introdução à Sociologia, em 1962, uma carta de Walter Benjamin a um destinatário então desconhecido (ADORNO, 1996, p. 197-198, 241), que, se saberia mais tarde, era Norbert Elias. A carta faz parte de breve correspondência entre Elias e Benjamin, sobre a possibilidade do segundo escrever uma resenha de Über den Prozess der Zivilisation na Revista de Pesquisa Social, cujos editores eram, entre outros, Horkheimer e Adorno. A resenha nunca chegou a ser escrita, apesar do pedido de Elias. A resposta de Benjamin argui as dificuldades impostas pela dedicação ao próprio trabalho (SCHÖTTKER, 1996). Seria o caso de lembrar também, no entanto, os embaraços que o próprio Benjamin enfrentava para ver seus trabalhos aceitos e publicados na mesma revista vinculada ao Instituto de Investigação Social, do qual era bolsista.

Enquanto Elias problematiza a diferença valorativa entre os conceitos de cultura e civilização, explorando os impasses e a fluidez dessa histórica e processual separação nas tradições alemã e de outros países, os frankfurtianos farão, em defesa da cultura, mas contra sua apatia, uma dura crítica à civilização. Para os membros do Instituto de Pesquisa Social, trata-se de compreender e criticar a civilização técnica, responsável por um tipo de mistificação que Adorno em outro momento chamará de véu tecnológico (ADORNO, 1997c). Em linguagem que em muito lembra Walter Benjamin, os autores recolocam a esperança de uma civilização que possa superar a si mesma: "Uma vez que a civilização se expanda e se liberte, de maneira que não haja mais qualquer faminto sobre a Terra, então ela terá realizado aquilo que a cultura até hoje em vão apenas prometeu" (INSTITUT FÜR SOZIALFORSCHUNG, p. 88).

\section{Retomando as Críticas de Elias}

As críticas de Elias a Adorno conduzem a pontos de tensão. Como já mencionado, é algo surpreendente a associação tão direta entre Adorno e ao marxismo, uma vez que muitos se dedicaram a desassociar tal perspectiva à Teoria Crítica, considerando que haveria, a partir dos trabalhos dos anos 1940, um rompimento definitivo de Adorno e Horkheimer com Marx.

É claro que Adorno e Horkheimer nunca estiveram próximos da vulgata marxista que sustentou as ações políticas de grande parte do movimento comunista do século XX. Já em Teoria Tradicional e Teoria Crítica - escrito por Horkheimer (1970), em 1936, simultaneamente às denúncias dos pogroms do stalinismo - está posta a crítica ao marxismo tornado ideologia de Estado. Horkheimer e Adorno foram sempre pensadores independentes do movimento comunista, que criticaram na prática política cega e aparentada com a violência e o totalitarismo. Da mesma forma, se seguramente um livro como Dialektik der Aufklärung está longe de qualquer vulgaridade teórica, não é possível pensá-lo em sua estrutura interna sem que se considere categorias marxistas, desde a troca de equivalentes 
como medida universalizada, até o fetichismo da mercadoria no contexto da indústria cultural. Do mesmo modo, são inúmeras as referências a Marx e à tradição marxista na obra de Adorno (por exemplo, 1972; 1997a), em especial na operação de conceitos como, entre outros, fetichismo, alienação, classe social e ideologia.

É, portanto, legítima e bem-vinda a afirmação de Elias, segundo o qual o humanismo crítico de Adorno estaria emoldurado por sua leitura de Marx, embora seja preciso destacar que esse humanismo crítico não tem apenas Marx como fonte, mas também, pelo menos, Kant, Nietzsche, Freud, Hegel. Equivocada, no entanto, porque em Adorno não há propriamente humanismo, pelo menos não em sentido enfático, uma vez posto seu claro distanciamento à Ontologia.

Das considerações de Elias sobre o marxismo de Adorno e suas decorrências, talvez elas possam ser sintetizadas em três pontos entre si interdependentes. O primeiro se refere ao fato de que Adorno não teria entendido por que as teorias de Marx se transformaram no contrário do que pretendiam, de modelo de ação para os oprimidos em processo legitimador para os opressores. O segundo trata das dificuldades que se teriam colocado para Adorno em entender esse processo, ao permanecer aferrado a um modelo teórico do século anterior - o próprio marxismo, o que o levaria à impossibilidade de continuar propondo novos problemas e alcançar soluções originais. Por último, trata-se de refletir sobre a ideia de que essa impossibilidade de pensar novas questões teria levado Adorno à resignação e à imobilidade do pensamento.

Dificilmente é possível concordar com a tese segundo a qual Adorno não teria entendido por que as ideias de Marx, cujo vetor era a emancipação dos trabalhadores pela transformação das relações sociais, transformaram-se em um movimento contrário, ligado à dominação e ao totalitarismo.

Adorno manteve-se fiel à crítica da sociedade burguesa como Marx (1982) a desenvolve em $O$ Capital, ao mesmo tempo em que criticou a adesão dos trabalhadores ao sistema capitalista, via benesses da social-democracia. Em outras palavras, Adorno foi, nesse sentido, como indicou Herbert Marcuse (1999), um marxista ortodoxo.

Ao permanecer fiel ao núcleo forte do marxismo como crítica, Adorno pôde perceber, nos marcos de sua crítica a dominação da natureza, o momento de violência presente no próprio marxismo, de sobrevalorização do avanço irrestrito das forças produtivas. Essa dominação irrefletida da natureza, representada pelo fetichismo da técnica e escondida pelo véu tecnológico, acaba por "autorizar" o totalitarismo, o domínio dos seres humanos, ainda que isso seja feito em nome de sua emancipação. Tal dialética, que Adorno (1997f) encontra na tensão produtiva entre o idêntico e o não-idêntico, entre o conceito e a experiência, considera que há, como escrito no início do texto, aludindo a Freud, um momento regressivo que não está fora, mas é parte irrenunciável do processo civilizador.

Outra ponderação a Elias relaciona-se com sua afirmação segundo a qual Adorno não teria observado que os processos de longo prazo não são completamente controláveis, precisamente porque o processo da civilização não é racional. É necessário reconhecer, como já salientado no início deste artigo, que com isso Elias não quer dizer que esse processo 
é irracional ou caótico, mas que ele não foi planejado de antemão de forma que pudesse como tal ser concretizado. Ao contrário, o conjunto de relações interdependentes estabelece configurações cada vez mais complexas que exigem uma adequação - essa sim em um sentido racional - tanto das disposições psíquicas individuais quanto das relações sociais. Não é esse o problema da crítica de Elias. Como dito, Adorno opera pela perspectiva dialética, segundo a qual um fenômeno histórico movimenta-se, negativamente, no sentido de sua transformação. Opera, em outras palavras, concebendo o mundo social como quadro de possibilidades não previsíveis, porque não conhecidas de antemão, mas engendradas pelas relações sociais entre classes e entre grupos sociais, entre ser humano e natureza, entre sujeito e objeto. Essas relações são complexas e multifacetadas, e, sobretudo, não isentas de dor, sofrimento, recalques, momentos de regressão e barbárie. Por isso a dialética de Adorno contrapõe-se a qualquer forma de reificação, ao mesmo tempo em que seu exercício crítico, ao denunciar o sofrimento, coloca-se em favor da utopia, e não da resignação, como quer Elias.

A perspectiva de Elias não pode ser considerada, nesse ponto, como excludente em relação à de Adorno. Mas, enquanto para Elias o domínio da natureza e o progresso são claramente positivos (1984), para Adorno trata-se de criticá-los em sua dialética, percebendo-lhes as contradições internas. Trata-se de verificar o potencial regressivo e produtor da barbárie presente no próprio progresso e no domínio da natureza, manifesto na opressão e na violência.

É bastante questionável, nesse sentido, a ideia de que Adorno tenha se refugiado na resignação, e que tanto ele quanto Horkheimer não foram firmes o suficiente para avançar no pensamento crítico. Inúmeras reflexões teóricas, bem como, uma série de pesquisas empíricas realizadas pelos Autores, em constante diálogo com o pensamento clássico, mas também com a Sociologia e a Psicologia contemporâneas, testemunham uma enorme produção intelectual, que se mantendo fiel ao rigor da tradição do Iluminismo, foi capaz de ser-lhe duramente crítica, mas também esperançosa em sua potência.

$\mathrm{Na}$ verdade, Adorno rejeitou a toda tentativa de reduzir o pensamento a sistemas fechados, como atesta um de seus grandes trabalhos da maturidade, a Dialética Negativa. É nesse sentido, precisamente, que para Adorno (1997f, p. 15) é preciso, antes de tudo, continuar pensando, afinal, a "Filosofia, que certa vez parecia superada, mantém-se em vida, uma vez que falhou seu momento de realização". Ao invés de resignação e incapacidade para seguir refletindo e propondo novas questões, o que ocorre com Adorno é o contrário: não há resignação frente ao irracionalismo ou à tibieza de leituras lineares da História, mas a obstinada recusa do presente, como crítica, por meio da qual segue a crítica e a proposição de novas questões.

Por fim, é de se destacar que, para além das questões apontadas neste pequeno texto, oriundas do discurso proferido por Elias, há outras que mostram aproximações e afastamentos entre os dois autores. O diálogo entre ambos, por meio de várias temáticas que lhes foram centrais - ou são hoje comuns nas tradições que a partir deles se desenvolveram -, pode constituir um eixo para seguir nesse profícuo debate acadêmico e, sobretudo, para 
pensar as questões do presente.

\section{REFERÊNCIAS}

ADORNO, Theodor W. Marx está superado? Vários Autores. Opções de Esquerda. Rio de Janeiro: Paz e Terra, 1972 (tradução de Carlos Nelson Coutinho).

ADORNO, Theodor W. Philosophische Terminologie (2 vol.) (Org. Rudolf zur LIPPE). Frankfurt am Main: Suhrkamp, 1974.

ADORNO, Theodor W. Introducción a la Sociología. Barcelona: Gedisa, 1996, p. 197198, 241 (tradução de Eduardo Rivera López).

ADORNO, Theodor W. Reflexionen zur Klassentheorie. Gesammelte Schriften (vol. 8). Frankfurt am Main: Suhrkamp, 1997a.

ADORNO, Theodor W. Zu Subjekt und Objekt. Gesammelte Schriften (vol. 10-2). Frankfurt am Main: Suhrkamp, 1997b.

ADORNO, Theodor W. Erziehung nach Auschwitz. Gesammelte Schriften (vol. 10-2). Frankfurt am Main: Suhrkamp, 1997c.

ADORNO, Theodor W. Was bedeutet: Aufarbeitung der Vergangenheit. Gesammelte Schriften (vol. 10-2). Frankfurt am Main: Suhrkamp, 1997d.

ADORNO, Theodor W. Kritische Theorie und Protestbewegung. Gesammelte Schriften (vol. 20-1). Frankfurt am Main: Suhrkamp, 1997e.

ADORNO, Theodor W. Negative Dialektik. Gesammelte Schriften (vol. 6). Frankfurt am Main: Suhrkamp, 1997f.

ADORNO, Theodor W. Kulturkritik und Gesellschaft. Gesammelte Schriften (vol. 10-1). Frankfurt am Main: Suhrkamp, 1997g.

ADORNO, Theodor W. Das Bewusstsein der Wissenssoziologie. Gesammelte Schriften (vol. 10-1). Frankfurt am Main: Suhrkamp, 1997h.

ARENDT, Hannah. Between Past and Future. London: Penguin Books, 1993.

ELIAS, Norbert. Adorno-Rede. Respekt und Kritik. ELIAS, Norbert; LEPENIS, Wolf. Zwei Reden anlässlich der Verleihung des Theodor W. Adorno-Preises 1977. Frankfurt am Main: Suhrkamp, 1977, p. 65-68.

ELIAS, Norbert. Über . den Prozess der Zivilisation. Frankfurt am Main: Suhrkamp, 1988 (2 vol.).

ELIAS, Norbert. Studien über die Deutschen. Frankfurt am Main: Suhrkamp, 1989.

ELIAS, Norbert. Reflections on a Life. Cambridge: Polity Press, 1994/Norber Elias Über sich selbst. Frankfurt am Main: Suhrkamp, 1996. 
ELIAS, Norbert. A Condição Humana. Difel: Lisboa, 1991 (tradução de Manuel Loureiro).

ELIAS, Norbert. "We have not learnt to control nature and ourselves enought: an Interwiew with Norbert Elias." Entrevista a Aafke Steenhuis, 1984. http://www.usyd. edu.au/su/social/elias/intervie.html. (tTradução do original em holandês por Robert van Krieken). Acesso em 15/11/2007.

HORKHEIMER, Max. Traditionelle und kritische Theorie. Vier Aufsätze. Frankfurt am Main: Fischer, 1970, p. 12-56.

HORKHEIMER, Max; ADORNO, Theodor W. Dialektik der Aufklärung. Philosophische Fragmente. Gesammelte Schriften (vol. 3). Frankfurt am Main: Suhrkamp, 1997.

INSTITUT FÜR SOZIALFORSCHUNG. Soziologische Exkurse. Hamburg, Europäische Verlagsanstalt, 1991, p. 88.

LEPENIES, Wolf. Ein Außenseiter, voll unbefangener Einsicht. In: ELIAS, Norbert; LEPENIS, Wolf. Zwei Reden anlässlich der Verleihung des Theodor W. Adorno-Preises 1977. Frankfurt am Main: Suhrkamp, 1977, p. 7-33.

MARCUSE, Herbert. Reflexões sobre Theodor Adorno. A Grande Recusa Hoje. Petrópolis: Vozes, 1999, p. 106-107 (Org. Isabel Loureiro, tradução da Organizadora e de Robespierre de Oliveira).

MARX, Karl. Das Kapital. Kritik der politischen Ökonomie. Berlim: Ditz, 1982.

SCHÖTTKER, Detlev. Norbert Elias und Walter Benjamin. Ein Briefwechsel und sein Zusammenhang. In: REHBERG, Karl-Siegbert. Norbert Elias und die Menschenwissenschaften. Studien zur Entstehung und Wirkunsgeschichte seines Werkes. Frankfurt am Main: Suhrkamp, 1996.

Submetido em: 20-8-2017

Aceito em: 5-3-2018 